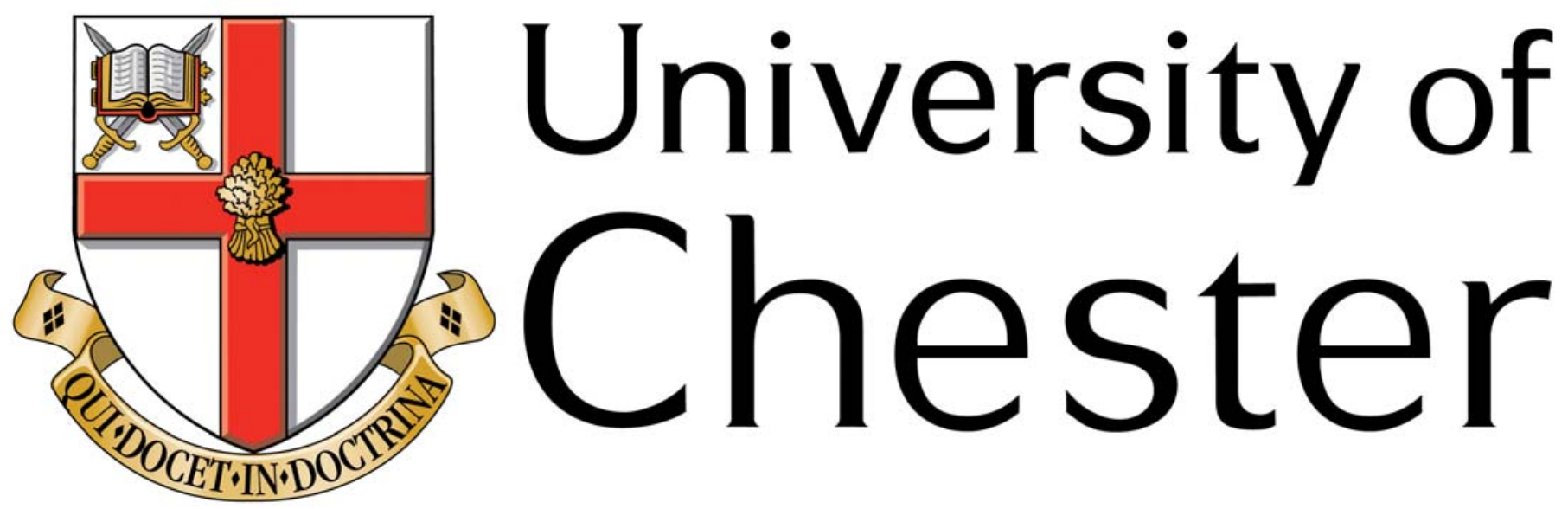

This work has been submitted to ChesterRep - the University of Chester's online research repository

\title{
http://chesterrep.openrepository.com
}

Author(s): Anne-Marie Wright

Title: Provision for students with learning difficulties in general colleges of further education - have we been going round in circles?

Date: 2009

Originally published in: British Journal of Special Education

Example citation: Wright, A-M. (2006). Provision for students with learning difficulties in general colleges of further education - have we been going round in circles?. British Journal of Special Education, 33(1), 33-39

Version of item: Author's post-print

Available at: http://hdl.handle.net/10034/6480 


\section{Provision for students with learning difficulties in general colleges of further education - have we been going round in circles?}

\section{Anne-Marie Wright}

\section{Introduction - setting the scene}

Provision for students with learning difficulties has existed in various guises in further education for more than two decades since it was first formally conceived by the Warnock Committee (DBS, 1978) and subsequently implemented through the 1981 Education Act (DBS, 1981). In the ensuing two decades, and particularly during the 1990s, the further education sector, now the learning and skills sector, has organically transformed in response to a relentless and rapidly implemented raft of large-scale policy changes at both national and local levels. The very identity of further education has been deconstructed from its original inception, described by Johnstone (1995) as a work-orientated training system designed principally to meet the needs of local commerce and industry, and has been reconstructed as a corporate, competitive, market-orientated provision in which educational ideals have become confused and, latterly, even subsumed by considerations of costeffectiveness and profit.

Notwithstanding the well-documented stresses resulting from such a rapid and, some may argue, clumsily managed change process, further education has responded within its new construction with unfailing enthusiasm to a 
stream of initiatives designed to reposition it as a provider of equality of opportunity, widened participation and barrier-free learning (FEFC, 1997). Yet despite this demonstrable commitment and a proactive approach to developing inclusive cultures embracing many minorities, there remains a group of students with special needs in further education who continue to be marginalised in separate and discrete provision.

One of the difficulties in discussing students who have special needs or learning difficulties is that the descriptive terminology assumes homogeneity and a common set of educational requirements. Descriptors such as 'special educational needs (SEN)' in schools or 'learning difficulties and/or disabilities (LDD)' in colleges promote an oversimplified, outdated way of thinking which not only carries pejorative inferences but is also singularly unhelpful in allowing focused debate (Corbett, 1998). In colleges, a wide and diverse group of individuals may find themselves enrolled on discrete programmes located under the broad banner 'students with learning difficulties and/or disabilities', even though their learning needs, previous educational experiences and vocational ambitions may be very diverse. In an attempt to provide a clear focus, this paper will concentrate on those students whose dominant educational need is related to a cognitive impairment manifested by difficulties in learning, commonly described as severe or complex learning difficulties (SLD) and for whom enrolment at a further education college may be their first mainstream experience. 


\section{Research aims}

This paper presents the findings from a critical review of literature combined

with a small-scale preliminary investigation. There is a lack of good quality, current research in this field. For reasons that are unclear, the educational community appears to have lost interest in this group of learners. The aim of this article is to reopen the debate by testing a contentious hypothesis which has emerged not from research, but from my own experience of working in the field in the last 20 years. My hypothesis is that, despite the new and radical conceptualisation of inclusive education combined with the reconstruction of further education, provision for students with severe learning difficulties in general colleges of further education has effectively lost its way; it is unfocused, at best circuitous and, at worst, leads individuals back into dependence, unemployment and social segregation.

\section{Research design}

My research involved three in-depth interviews with practitioners who were chosen not only for their wealth of experience in working directly with students with severe learning difficulties in colleges of further education before and after incorporation, but also for their work at a national level. It was assumed that they would not only be able to describe their personal experience of working with students with severe learning difficulties, but would also be able to explore and analyse issues through an understanding of the wider legislative and philosophical context. First, responses were obtained through open-ended questions and dialogue and were then transcribed. Second, I extracted common themes in the responses based on reflective analysis and 
interpretation of the research participants' comments (Georgi, 1985, cited in Moustakas, 1994). This research design was based in phenomenology which has often been employed by researchers in the area of special educational needs to capture subjective personal experience, for example, 'how a student has experienced inclusion'. Phenomenology places the experience of the individual at the centre of the enquiry and seeks to understand and describe that experience from the point of view of the participant (Mertens \& McLaughlin, 1995; Creswell, 1998). Phenomenology seemed the most appropriate method to use to capture the truth of the 'lived' experiences of practitioners in that it supported them in reflecting, exploring and analysing without constraint or preconception.

\section{A review of the literature}

The beginnings

As with so many things connected with special needs education in the last two decades, the roots of the work that is the focus of this article are in the Warnock Report (DES, 1978). Warnock's reflections and subsequent regrets about her recommendations for the Statementing of school age pupils have often been discussed (Warnock, cited in Visser \& Upton, 1993). Interestingly, her recommendations for post-compulsory education were based on the supposition that the provision of all education, including provision for those with special needs up to the age of 19 , would be the responsibility of local education authorities (LEAs). The fact that incorporation through the Further and Higher Education Act (DfE, 1992) shifted this responsibility away from LEAs to independent corporate management might be one of the reasons 
why Warnock's vision for a flexible continuum of integrated provision for the post-compulsory sector has never been fully realised.

The Warnock Report (DES, 1978) was the first official publication to argue for continued education after compulsory schooling for young people with learning difficulties. It recommended that the educational and training needs of young people described at the time as having 'special educational needs' should be met through a menu of 'ordinary' if 'modified' courses; by 'some special vocational courses'; and through 'training in social competence and independence' (DES, 1978).

The Warnock Report was, by and large, received positively and its recommendations were widely adopted throughout the early 1980s. Despite the absence of national policy or any strategic planning for additional resourcing (Stowell, 1988), colleges of further education established courses for students with special needs which thrived and rapidly expanded (Stowell, 1987; Dee, 1993). Stowell (1987) recalls that the first courses were designed predominantly for students who had transferred, aged 16 , from special schools for pupils with moderate learning difficulties (MLD) and subsequently came to accommodate those with more severe needs transferring, aged 19, from transition units in special schools for pupils with severe learning difficulties (SLD). The design of the curriculum was rooted in what Johnstone (1995) described as 'the evolutionary model of the negotiated curriculum' developed by the Further Education Unit (FEU, 1986) which was based in humanism and founded in the popular rhetoric of student need. 
The roots and origins of the discrete 'life skills' model of curriculum

Corbett and Barton (1992) describe the genuine belief, which prevailed at the time, that the mainstream vocational and academic curriculum was inaccessible to students with learning difficulties. Hewitson (1998), in tracing these earliest phases of special curriculum development, asserts that what was to become regarded as good practice, in terms of the construction of courses and learning programmes, grew from pockets of pioneering work in the late 1970 s by lecturers who had come out of special schools. They developed curricula loosely based on Warnock's ideas but which were significantly influenced by the curriculum model applying in special schools for pupils with severe learning difficulties at the time. As their ideas developed, they were disseminated and extended through a series of curriculum guides produced by the Department of Education and Science (DES)'s Further Education Unit (FEU) throughout the 1980s. A College Guide (FEU, 1986) advocated courses which 'should offer a platform for growth in self-confidence and promote home and community recreation ... which should be taught alongside work skills' and described courses as typically being built around 'using public transport, timekeeping, personal hygiene and decision-making skills'. From Coping to Confidence (DBS, 1985) offered a teaching support pack and Stowell's seminal work, Catching Up (1987), presented a comprehensive survey of students with learning difficulties in further education. The DES produced a report entitled A Special Professionalism (DES, 1987) which provided a blueprint for raising cross-college awareness firmly lodged in the Warnock tradition of integration (Harris \& Clift, 1988). Mittler (2003), reflecting some 15 years on, regards A Special Professionalism 
as 'far superior in breadth and quality to any comparable publication for teachers and other staff working with school-age children at that time' and reflects generally that:

'although these guides were unique at the time in supporting the planning and implementation of a whole college approach and in developing inclusive curricula ... the guidance was not always implemented or followed up in the colleges so that many of these documents were neither known nor used.' (p. 180)

So, despite the rhetoric which continued to argue for Warnock's clear recommendation for a flexible continuum of integrated provision, the majority of courses remained 'discrete, separate and modified' (Dee, 1993) and were often 'confined to improving general life skills or else leisure pursuits such as art, pottery and dressmaking' (Stowell, 1988). The reasons for colleges' apparent unwillingness to challenge a curriculum which seemed to be moving further and further away from the mainstream, removing the possibilities for integration, are unclear. Mittler (2003) reflects that, in the same period, 'integration' transformed from its original meaning as involvement in mainstream curricula; took on a less challenging definition; and came to be understood and accepted as general participation in college life. Colleges also appeared to ignore the Department for Education and Science's (DES, 1989) directive for a changed concept of special educational needs. This sought to move practice away from discrete and different provision towards 'integrated' mainstream provision which, it was suggested, could be achieved by providing assessed and resourced additional support based on the identification of individual need. This idea essentially mirrored the situation in schools, which had already moved to a national 'entitlement' curriculum 
through the Education Reform Act (ERA) (DES, 1988) and where separate, special curricula had been superseded.

\section{The early 1990s - missed opportunities and misunderstandings}

In the early 1990s, the concept of 'integration' was replaced in the practitioner community by a philosophy of 'inclusion', spurred on by governmental commitment to the Salamanca Statement (UNESCO, 1994) and disseminated through the Green Paper Excellence for All (DfES, 1997) and the subsequent guidance Meeting Special Educational Needs: a programme for action (DfES, 1998). These documents heralded the beginnings of the current wave of radical change for special needs education in schools.

The sea change for the further education sector, promoted through the Further and Higher Education Act (DfE, 1992), brought with it a new funding mechanism described by Johnstone (1995) as 'the mechanism through which the FEFC could steer the emerging culture of enterprise and competition'. The Act introduced the descriptor 'students with learning difficulties and/or disabilities (LDD)' and the new terminology carried with it a changed focus on 'learning' needs rather than special 'medical' needs. This was seen as signposting a new way of thinking likely to lead to a more radical approach to the curriculum. However, perhaps because college leadership was understandably preoccupied with establishing a new corporate identity, real change for students with learning difficulties, apart from the new label, did not happen. Four years later, largely because there had been no complete description or overview of provision inherited from LEAs, the Tomlinson 
Committee (Tomlinson, 1996) set out to 'reconceptualise provision for students with learning difficulties' with a declared mission to make:

'the final step, on the long march towards embracing students with learning difficulties and/or disabilities fully and unequivocally within the general approach to learning appropriate for all students.' (p. 1)

The Tomlinson Report was followed by a two-year period of intensive national dissemination, the impact of which has been reported extensively by the Learning and Skills Development Agency (LSDA, formerly FEDA). The principle of shifting funding away from specialist courses to the individual resulted in much improved arrangements for students with sensory and physical impairments and specific learning difficulties (FEDA, 1998; Anderson, Faraday, Prowne, Richards \& Swindels, 2003). However, although the inclusive learning initiative did much to influence colleges' attitudes, understanding and ultimately their cultures, it did not have the same positive impact on discrete provision for students with severe learning difficulties. The reasons for this are difficult to deconstruct but could be attributed, in part at least, to the new and complex funding mechanism of the time.

It was understood that all non-vocational courses, including those prevocational courses which may ostensibly eventually lead to a nationally recognised qualification, would attract funding listed under the Further and Higher Education Act (DfE, 1992) as 'Schedule 2'. In this way, funding for students with learning difficulties was linked to the student's ability to show evidence of such progression towards a higher level qualification (Johnstone, 1995). This forced managers of provision for students with learning difficulties 
into an untenable position of fusing two sets of seemingly incompatible demands: the push from the colleges' corporate management to attract maximum funds for their institution and the need to provide appropriate learning opportunities for students with learning difficulties. Many colleges chose to interpret the new funding directives as explicit instructions to create pre-vocational courses leading to a recognised award or qualification which could attract funds through Schedule 2(d) (a course which prepares students for entry to another course). At the time, the FEFC (Faraday, 1996) also signalled a rather ambiguous directive in a pamphlet Assessing the Impact that colleges should adopt Schedule 2 courses for all learners with learning difficulties: 'The list of types of courses eligible for funding by the FEFC includes some which may be particularly relevant to learners with learning difficulties.'

Achievement at the time for students with learning difficulties had been traditionally recognised by Records of Achievement and 'in house' college certificates. Awarding bodies began to respond to colleges' demand for Schedule 2 courses by providing a plethora of awards at pre-foundation level designed to lead to their already established higher level awards in the national qualifications framework (QCA, 2004). Many of those who adopted the new award-based progression structure planned curricula around the performance criteria set by the awards and lost sight of the previously established reliance on individual learning plans modelled by special schools. There was a sincere belief among a substantial group of managers of provision for students with learning difficulties that these awards provided 
parity of esteem for learners with learning difficulties with their mainstream peers and they saw a chance to raise the profile of these learners with future training providers and potential employers.

A positive side product, from the college management point of view, which perhaps had not been predicted (at least not in departments making provision for students with learning difficulties), was that courses leading to externally accredited awards attracted two funding streams: first, Schedule 2 funding under 2(d) and, second, additional learning support (ALS) units of funding, often at the highest levels, attached to each individual student. This resulted, in many instances, in unsurpassed income generation for colleges 'on the back' of courses designed for students with learning difficulties. Not surprisingly, discrete provision continued to grow and the impetus and previous motivation for a more integrated model of provision seriously waned. Furthermore, this phenomenon worked directly against the FEFC's original intention to shift funding away from specialist courses and towards a model of individual funding to support mainstream integration. Dee and Corbett (1994) had accurately predicted what actually happened to provision for students with learning difficulties in colleges. They foresaw the likelihood that:

'at best the funding mechanism was open to anomalous interpretation and at worst, potentially provided an opportunity for abuse and would eventually lead to inequity for students.' (p. 321)

Indeed, the results of a curriculum led by an award structure designed to provide progression to mainstream Level 1 courses which was in turn driven by a misinterpreted and possibly misused funding system, proved to be 
disastrous for students with severe learning difficulties and their lecturers. A disproportionate amount of time was spent assessing award-based courses under D32 and D33 requirements. The collection of evidence was onerous and inappropriately focused on paper-based systems, often involving written transcripts ostensibly produced by students who could neither read nor write. This loss of meaningful learning opportunities for students and many weaknesses in teaching subsequently identified by FEFC and OFSTED inspections have been, and continue to be, directly attributed to the use of awards which do not provide a framework for what students really need to learn. In a sense, equity, rather than being understood as 'fairness', had been confused with 'sameness'. Courses were established as discrete and removed from the vocational provision of colleges; many were taught in unsuitable accommodation by non-specialists and the separateness of students with learning difficulties from the mainstream was further compounded.

In 1999, the FEFC published a report, National Awards for Students with Learning Difficulties (FEFC, 1999a), which stated that:

'many colleges mistakenly thought that external awards were necessary to meet the requirements of Schedule 2 ... to secure funding from the FEFC and to meet the requirements of their own management information systems.' (p. 1)

At the same time, the FEFC (1999b) issued Circular 99/10, Schedule 2, confirming that funding for learners with learning difficulties was not dependent on them studying for external awards. 


\section{Where are we now?}

Current inspection reports would indicate that there have been some improvements in provision for students with learning difficulties in recent years but many significant weaknesses remain. Information taken from the specialist sections of a selection of colleges' OFSTED reports highlight the following key strengths:

- specialist accommodation and access to therapists and augmented communication;

- productive external partnerships;

- vocational courses sited in well-equipped vocational departments in the college;

- effective specialist support;

and these key weaknesses:

- $\quad$ underqualified staff - little specialist training;

- inappropriate and poor accommodation;

- overemphasis on accredited provision;

- $\quad$ rigid and inappropriate curriculum;

- limited and undemanding targets for improvement;

- insufficient diagnostic assessment;

- underdeveloped individual learning plans;

- insufficient use of information and communication technology (ICT). 
The picture at the time of writing seems to be the one described by Browne (2002) in which students with severe learning difficulties are generally welcomed, but as a hidden minority; are allocated to their own classrooms, often following non-accredited programmes; and are separated from the higher profile courses offered by the institution. Repeated attempts to deliver more integrated practice in the 1990s and the current desire to develop more inclusive cultures would appear to have systematically failed to reach learners with the most complex needs. Provision for students with learning difficulties, in its current dichotomous position as part of the new inclusive doctrine of special educational needs set against the still persisting competitive bidding culture of the learning and skills sector (Ainley, 2003), has been relatively unexplored.

\section{What did the interviews reveal?}

Three in-depth interviews were undertaken, as described earlier, using one broad question which allowed respondents to draw on their extensive experience to reflect upon and try to explain the current weaknesses (and strengths) in the provision. The interviews were conducted separately and the three participants did not know or meet each other. As interviewer, I transcribed the interviews and then extracted common themes in the responses.

There was a clear consensus that provision for learners with severe learning difficulties is generally poor, lacks vision, is unfocused, is excluded from strategic planning and currently fails students. There is no national policy or 
guidance for good practice and this has led to local differences in the quality and nature of provision. Provision was described as: 'Pretty poor - everywhere - everywhere / go.'

A more optimistic view acknowledged that, even where the curriculum is well designed and effective, students are 'marooned' in separate provision with little opportunity for progression through the qualifications framework. There was agreement that there is no established infrastructure to support effective partnerships to ensure transition to work or independent living and colleges are generally working in isolation. Lack of effective partnerships with social services, Connexions, employment providers, employers, health authority and housing were all mentioned. This has led to depressed achievement for students attending courses which are, at best, wasted and, at worst, almost meaningless and lead nowhere. As one interviewee said:

'It is just so unsatisfactory and so dead end for those young people and deeply frustrating ... that you can't see where it's all leading - that's quite hard going sometimes to just know that there isn't much of a next step for people who are graduating from us.'

Because of the lack of rigour and coherence in the supporting services, for many learners, it would seem that the experience of further education is cyclical or static and students are unable effectively to maintain skills after they leave a two or three-year college course. One example was given of a student attending the same course for six years with the majority of learners returning to day service provision with little opportunity to build on skills and qualifications gained at college. 
Teachers often work in isolation and lack the qualifications and financial rewards of their peers working in the schools sector, although, when teaching is good, it is because of the skills of charismatic and gifted teachers rather than as a result of effective training in good practice. As one interviewee stated:

'Everything is still cobbled together and good provision seems to exist in pockets and is dependent on good teachers working in relative isolation.'

More positively, where provision is good it would appear that there is clear vision and strong leadership, which is holistic and is an integral part of wholecollege planning:

'To make it work, all sorts of things interlink and interweave and you need somebody at the top knowing that and releasing resources, making sure the money and the equipment are there. Any work that focuses purely on this provision in isolation could only be tinkering round the edges.'

In this way, good practice must be borne from a conceptualisation of the work as part of an inclusive, holistic provision. This means that courses for students with learning difficulties must link to a wide range of vocational areas and provide opportunities for real or simulated vocational experience. They must also provide opportunities for concrete practical learning. There was a consensus among my interviewees that this kind of provision is rare.

In summary, the interviews provided the following information: 
- Provision for learners with severe learning difficulties remains discrete and unconnected to the mainstream qualifications framework.

- Opportunities for progression to independent living are poor or nonexistent.

- Links to supported employment providers are inadequate.

- Excellent provision is rare but where it exists it is characterised by:

- learners being valued and afforded status as equals;

- the pre-vocational curriculum being led by learners' aspirations;

- charismatic and committed teaching;

- effective support for risk taking.

\section{Conclusions and next steps}

Although my review of literature includes wider-reaching judgements made on the provision by OFSTED, the research presented in this paper has been small-scale. The hypothesis set out at the start of the article, that provision for students with severe learning difficulties in colleges of further education has been 'going round in circles', has been largely confirmed but clearly has not been empirically proven. Its defence and validity is as a useful 'litmus test' which has provided a valid insight into the broader picture. There are, no doubt, exceptions across the country where provision is clearly linked to learners' aspirations and where transition to employment and independent living is well managed. Nonetheless, a reading of OFSTED reports will support the findings of this research that these colleges are in the minority. 
There is a clear and indisputable need for academics and educationalists to recommit to the energy that was evident in the research and writing of the 1980s and early 1990s. As a starting place, research might focus on listening to learners. Allowing students with severe learning difficulties a voice with which to explore their hopes and aspirations in terms of learning, employment, leisure, living and relationships can provide perspectives to set these against the reality of the learning programmes and individual targets set by colleges. College staff could then assess the level of coherence and 'fit' or mismatch. At the centre of this debate there is a group of individuals who would seem to have lost their voice. One imagines that, if given the opportunity, they would have very clear ideas about their hopes and plans for adult life. It is all too easy for these students to enjoy the exciting and 'heady' freedom of the dayto-day experience of student life without considering the longer-term position. If students were told at the beginning of their course that after three years their future would be in day care provision and this was a concept that they could fully understand, one wonders if they would be so receptive to the rather meaningless 'circuitous' learning opportunities often provided for them in college. As one interviewee said:

'Our special needs students do not have a voice. If they like the person [teacher] they would never say anything horrid like the fact that we have been bored the whole lesson.'

If further education is serious about continuing to provide an inclusive experience for students with severe learning difficulties by providing courses which respond effectively to their real needs, it must commit not only to providing learning which meets the needs and aspirations of learners but it 
must also work once again to strengthen partnerships with providers of employment and other services. Rather than allowing students to revisit comfortable, unchallenging experiences, colleges need to refocus and see the bigger, longer-term picture. Imagine an 'Access' course which did not provide careers guidance or support for applications for places in higher education and which did not link with a local university. Why should there be a difference for learners with severe difficulties?

It would seem that the experience of students with severe learning difficulties in general colleges of further education remains characterised by segregation, patronisation and inequity. This is an intolerable and unsustainable situation not only for this group of learners but for the sector as a whole. Over ten years ago Dee and Corbett (1994) suggested that 'it is not enough for these learners to be considered merely as legitimate participants.' Dee and Corbett argued that they should be seen as 'being sufficiently important to contribute to more flexible ways of operating, being respected and really included in an acceptable framework'. Has any real progress been made in recent years? Has the enticement of the funding-led culture of incorporation distracted us to the extent that this statement continues to be true? Have we really just been going round in circles?

\section{References}

Ainley, P. (2003) 'Towards a seamless web or patching over the cracks', Journal of Educational Studies, 51 (4), 390-407.

Anderson, V., Faraday, S., Prowne, S., Richards, G. \& Swindels, D. (2003) Count me in FE. London: LSDA.

Browne, L. (2002) 'Listening to the student: a small scale study of inclusive practice in a college of further education', Support for Learning, 17 (2), 70-74. 
Corbett, J. (1998) Special Needs in the Twentieth Century: a cultural analysis. London: Cassell.

Corbett, J. \& Barton, L. (1992) A Struggle for Choice: students with special needs in transition to adulthood. London: RoutledgeFalmer.

Creswell, J. W. (1998) Qualitative Enquiry and Research Design: choosing among five traditions. Thousand Oaks, CA: Sage.

Dee, L. (1993) 'What happens after school?', in J. Visser \& G. Upton (eds) Special Education in Britain after Warnock. London: David Fulton Publishers.

Dee, L. \& Corbett, J. (1994) 'Individual rights in further education: lost, stolen or strayed?' British Educational Research Journal, 20 (3), 319-325.

DES (Department of Education and Science) (1978) Special Educational Needs: report of the committee of enquiry into the education of handicapped children and young people (The Warnock Report). London: HMSO.

DES (Department of Education and Science) (1981) The Education Act 1981. London: HMSO.

DES (Department of Education and Science) (1985) From Coping to Confidence. London: DES.

DES (Department of Education and Science) (1987) A Special Professionalism: report of the further education teacher training working group. London: HMSO.

DES (Department of Education and Science) (1988) The Education Reform Act. London: HMSO.

DES (Department of Education and Science) (1989) Education Observed 9: students with special needs in further education. London: HMSO.

DfE (Department for Education) (1992) Further and Higher Education Act. London: HMSO.

DfES (Department for Education and Skills) (1997) Excellence for All: meeting special educational needs. London: DfES.

DfES (Department for Education and Skills) (1998) Meeting Special

Educational Needs: a programme for action. London: DfES.

Faraday, S. (1996) Assessing the Impact: provision for learners with learning difficulties and disabilities. Dorchester: Henry Ling for FEFC.

FEDA (Further Education Development Agency) (1998) Inclusive Colleges: building on inclusive practice. Bulletin 2 [available online in the FEDA archives at http://www.Isda.org.uk].

FEFC (Further Education Funding Council) (1997) Learning Works: widening participation in further education colleges (The Kennedy Report). Coventry: FEFC.

FEFC (Further Education Funding Council) (1999a) National Awards for Students with Learning Difficulties (National Report from the Inspectorate). Coventry: FEFC.

FEFC (Further Education Funding Council) (1999b) Circular 99/10, Schedule 2. Coventry: FEFC.

FEU (Further Education Unit) (1986) A College Guide: meeting special educational needs. York: Longman for FEU.

Harris, R. \& Clift, J. (1988) 'Into the subculture of FE: some observation on the role of staff development in the evolution of special needs provision', The Vocational Aspects of Education, XI (107), 105-110. 
Hewitson, C. (1998) At the Verge of Inclusiveness: a study of learning support in post compulsory education. Hampshire: Ashgate.

Johnstone, D. (1995) Further Opportunities: learning difficulties and disabilities in further education. London: Cassell.

Mertens, D. M. \& McLaughlin, J. A. (1995) Research Methods in Special Education. Thousand Oaks, CA: Sage.

Mittler, P. ( 2003) Working Towards Inclusive Education: social contexts. London: David Fulton Publishers.

Moustakas, C. (1994) Phenomenological Research Methods. London: Sage.

QCA (Qualifications and Curriculum Authority) (2004) Entry Level Qualifications [online at http://www.qca.org.uk].

Stowell, R. (1987) Catching Up? London: National Bureau for Students with Disabilities/SKILL.

Stowell, R. (1988) 'The student population in further education', The Vocational Aspect of Further Education, XL (107), 101-104.

Tomlinson, J. (1996) Inclusive Learning -principals and recommendations: a summary of the findings of the learning difficulties and disabilities committee. Coventry: FEFC.

UNESCO (1994) World Conference on Special Needs Education: access and quality. Paris: UNESCO.

Visser, J. \& Upton, G. (1993) Special Education in Britain after Warnock. London: David Fulton Publishers.

\section{Note}

Reports from inspections of individual colleges of further education, together with annual reports into provision for learners with learning difficulties and/or disabilities across the sector, can be accessed at the OFSTED web site: www.ofsted.gov.uk. 